\title{
RESISTÊNCIA DOS CAMARÕES MARINHOS LITOPENAEUS VANNAMEIE FARFANTEPENAEUS SUBTILIS A INFECÇÕES POR VIBRIO HARVEYI
}

\author{
JOANA LYRA VOGELEY, ROBERTA NERY, BRUNA DO VALLE, FREDDY VOGELEY, \\ JOSÉ VITOR LIMA, ROBERTA SOARES, SILVIO PEIXOTO \\ Universidade Federal Rural de Pernambuco, Departamento de Pesca e Aquicultura, Laboratório de Tecnologia em Aquicultura - LTA, Av. Dom \\ Manoel Medeiros S/N, Dois Irmãos, Recife (PE), Brasil. CEP: 52171-900, joanavogeley@hotmail.com
}

\section{RESUMO}

Nos camarões peneídeos, doenças causadas por bactérias do gênero Vibrio resultam em baixas taxas de sobrevivência nos sistemas de larvicultura, berçário e engorda. O objetivo desse estudo foi avaliar a resistência de juvenis de Litopenaeus vannamei e Farfantepenaeus subtilis a uma infecção experimental pela bactéria Vibrio harveyi. Os camarões foram expostos por um período de 96 horas a três concentrações de V.harveyi inoculado diretamente na água: 103, 106 e 109 UFC mL-1, e um controle sem adição de V.harveyi. Três repetições foram usadas para cada tratamento. Para quantificação do total de Vibrio spp., foram coletadas amostras de água e de camarões de cada tratamento ao final do experimento. Não houve diferença significativa na sobrevivência do $L$. vannamei e $F$. subtilis quando comparado ao tratamento controle. Ambas as espécies apresentaram menor sobrevivência no tratamento 109 UFC mL-1, com $93 \%$ e 83\%, respectivamente para $L$. vannamei e $F$. subtilis. Houve um aumento na concentração total de Vibrio nos camarões submetidos à maior concentração de V.harveyi (109 UFC $\mathrm{mL}-1$ ). Os resultados sugerem que as concentrações da linhagem de V.harveyi utilizada não afetaram a sobrevivência dos camarões nesse estágio de vida durante o período avaliado.

PALAVRAS CHAVE: Vibrio harveyi, infecção, sobrevivência, Litopenaeus vannamei, Farfantepenaeus subtilis

\section{ABSTRACT}

Resistance of Litopenaeus vannamei and Farfantepenaeus subtilis to infection by Vibrio harveyi In penaeid shrimp, diseases caused by Vibrio species are usually associated with low survival in larviculture, nursery and growth systems. The objective of this study was to evaluate the resistance of Litopenaeus vannamei and Farfantepenaeus subtilis juveniles to an experimental infection by V.harveyi. Shrimp were exposed during 96 hours to three concentrations of V.harveyi inoculated directly in the water: 103, 106 and 109 CFU mL-1 and a control without addition of V.harveyi. Three replicates were used for each treatment. Samples of water and shrimp were collected from each treatment at end of the experiment to estimate Vibrio spp. counts. There was no significant difference in survival of $L$. vannamei and $F$. subtilis when compared to control. Both species had lower survival in the treatment $109 \mathrm{CFU} \mathrm{mL}-1$, with $93 \%$ and $83 \%$, respectively for $L$. vannamei and $F$. subtilis. There was an increase in the total concentration of Vibrio spp. in shrimp submitted to the highest concentration of V.harveyi (109 CFU mL-1) in the water. The results suggest that the concentrations of this V.harveyi strain did not affect shrimp survival at this life stage during the study period.

KEYWORDS: Vibrio harveyi, infection, survival, Litopenaeus vannamei, Farfantepenaeus subtilis.

\section{INTRODUÇÃO}

A partir da década de 80 houve a consolidação e o crescimento mundial do cultivo do camarão marinho, principalmente da espécie Litopenaeus vannamei, decorrentes do avanço de novas tecnologias de reprodução em cativeiro e larvicultura, assim como da crescente demanda do produto no mercado internacional (Rocha \& Rodriguez 2004). Porém, a intensificação da carcinicultura vem sendo acompanhada pela ocorrência de doenças, destacando-se aquelas causadas por bactérias patógenas oportunistas (Moriarty 1998; Gomez-Gil et al. 2000), as quais são frequentemente associadas com baixas taxas de sobrevivência em sistemas de larviculturas e engorda (Saulnier et al. 2000).

Entre as bactérias potencialmente patógenas, as do gênero Vibrio tem sido as principais responsáveis por doenças e altas taxas de mortalidade em camarões cultivados (Baticados et al. 1990). Espécies como Vibrio harveyi podem infectar larvas, juvenis e adultos de camarões peneídeos (Gomez-Gil et al.
1998; Lavilla-Pitogo et al. 1998), comprometendo a cadeia produtiva. A abundância natural de Vibrio spp., assim como sua ubiquidade, taxa de multiplicação e habilidade para adaptar-se a mudanças ambientais em sistemas aquícolas, ressaltam a importância da avaliação de seus efeitos patogênicos em camarões cultivados (Saulnier et al., 2000).

A domesticação de espécies selvagens de camarão e sua introdução bem sucedida na indústria da carcinicultura requerem um conhecimento profundo da biologia destas espécies, especialmente no que diz respeito à nutrição, reprodução e saúde (Brock \& Main 1994). O camarão-rosa Farfantepenaeus subtilis é uma espécie nativa da costa norte e nordeste brasileira e que vem sendo considerada com potencial para a aquicultura nacional (Nunes et al. 1997). Logo, o conhecimento acerca da resistência desse camarão aos agentes patógenos é de fundamental importância para o setor produtivo. No entanto, pouca informação está 
disponível sobre o impacto de infecções bacterianas em camarões nativos de águas costeiras brasileiras. Neste sentido, o objetivo do presente estudo foi avaliar a sobrevivência de juvenis de L. vannamei e $F$. subtilis quando expostos ao $\mathrm{V}$. harveyi.

\section{MATERIAIS E MÉTODOS}

Os juvenis de camarões $L$. vannamei $(0,25 \pm 0,06 \mathrm{~g})$ e $F$. subtilis $(0,25 \pm 0,03 \mathrm{~g})$, foram obtidos em laboratórios comerciais nos estados de Pernambuco e Rio Grande do Norte, respectivamente. Os indivíduos foram expostos por um período de 96 horas a três concentrações de $V$. harveyi inoculado diretamente na água, seguindo os seguintes tratamentos com três repetições cada: $10^{3}, 10^{6}$ e $10^{9}$ Unidades Formadoras de Colônia $\mathrm{mL}^{-1}$ (UFC $\mathrm{mL}^{-1}$ ) e um controle sem inóculo de $V$. harveyi. $O V$. harveyi utilizado para infecção da água das unidades experimentais foi obtido do banco de cepas do Laboratório de Camarões Marinhos - Setor Microbiologia, Departamento de Aquicultura da Universidade Federal de Santa Catarina. A cepa de $V$. harveyi foi mantida em meio TSB (Tripic Soy Broth HIMEDIA $^{\circledR}$ ) enriquecido com $2,0 \%$ de $\mathrm{NaCl}$ e acrescido de $30 \%$ de glicerol, e estocada em freezer a $-80^{\circ} \mathrm{C}$ no Laboratório de Sanidade dos Organismos Aquáticos UFRPE.

O experimento foi realizado no Laboratório de Tecnologia em Aquicultura (LTA) da UFRPE. Foram utilizadas quatro unidades experimentais, correspondendo a cada tratamento, que consistiram de caixas plásticas com volume de 12L, aeração constante e temperatura ambiente. Em cada caixa foram distribuídos seis potes plásticos de $500 \mathrm{~mL}$ (subunidades) revestidos com tela de nylon $(100 \mu \mathrm{m})$ como repetições de cada tratamento, sendo três para estocagem de $L$. vannamei e três para $F$. subtilis. Em cada subunidade foram estocados 10 camarões, totalizando 30 animais por espécie. A água utilizada no experimento foi previamente filtrada em malha de 0,1 $\mu \mathrm{m}$ e desinfetada com hipoclorito de sódio (20 ppm). Os indivíduos de ambas as espécies foram expostos à mesma concentração de $V$. harveyi, inoculado no volume total das unidades experimentais. Os camarões foram alimentados na proporção de $10 \%$ da biomassa duas vezes ao dia (manhã/tarde) com ração comercial com 35\% de proteína bruta (Purina MR35).
O V. harveyi utilizado na infecção foi primeiramente cultivado em Caldo Cérebro-Coração $(\mathrm{BHI})$ durante $24 \mathrm{~h}$ em estufa $\left(30{ }^{\circ} \mathrm{C}\right)$. Após esse período, foi efetuada a quantificação bacteriana da cultura através de diluições decimais seriadas $(1 / 10)$ de uma amostra em solução salina estéril (2,5\% $\mathrm{NaCl}$ ). A partir de cada diluição, uma alíquota de 100 $\mu \mathrm{L}$ foi retirada para plaqueamento em Agar Tiossulfato Citrato Bile Sacarose (TCBS) e, após o período de incubação de $24 \mathrm{~h}$ em estufa $\left(30^{\circ} \mathrm{C}\right)$, foi feita a contagem das Unidades Formadoras de Colônia. Após a determinação do número de UFC $\mathrm{mL}^{-}$ ${ }^{1}$ dessa cultura de $V$. harveyi, a mesma foi diluída serialmente nas parcelas experimentais a fim de se obter as concentrações $10^{3}, 10^{6}$ e $10^{9}$ UFC $\mathrm{mL}^{-1}$, conforme os tratamentos propostos. Diariamente, amostras de água foram coletadas de cada unidade experimental e semeadas seguindo o mesmo protocolo citado anteriormente, a fim de garantir a manutenção das concentrações bacterianas determinadas para cada tratamento.

A quantificação de Vibrio nos camarões foi realizada em ambas as espécies antes e após a exposição dos animais ao $V$. harveyi. Os indivíduos foram coletados diretamente das unidades experimentais, dispostos sobre uma peneira desinfetada e lavados com solução salina $(2,5 \% \mathrm{NaCl})$ esterilizada para remoção das bactérias externas. Os animais foram pesados em balança analítica, macerados e em seguida um volume correspondente a dez vezes o peso dos animais (1:10, Peso:Volume) foi adicionado de solução salina estéril (2,5\%) para perfazer a diluição $10^{-1}$. Posteriormente, a amostra foi diluída e semeada conforme descrito para análise de água.

Os valores de sobrevivência dos camarões e concentração de Vibrio spp. foram submetidos a análise de variância (ANOVA), levando em consideração as premissas necessárias, e ao teste de Tukey para verificar diferenças significativas entre os tratamentos $(p<0,05)$.

\section{RESULTADOS}

Os resultados de quantificação diária de Vibrio spp. da água dos diferentes tratamentos demonstraram que, durante as 96 horas experimentais, as concentrações mantiveram-se estáveis em cada 
tratamento $\left(10^{3}, 10^{6}\right.$ e $10^{9}$ UFC $\left.\mathrm{mL}^{-1}\right)$. As infecções por $V$. harveyi não resultaram em diferenças significativas na sobrevivência do L. vannamei e $F$. subtilis quando comparado ao tratamento controle. Entretanto, os camarões apresentaram menor sobrevivência no tratamento $10^{9} \mathrm{UFC} \mathrm{mL}^{-1}$, com $93 \%$ e $83 \%$, respectivamente para $L$. vannamei e $F$. subtilis (Figura 1). Além disso, os camarões $L$. vannamei do tratamento $10^{3}$ UFC $\mathrm{mL}^{-1}$ apresentaram uma sobrevivência superior do que aqueles mantidos sem a presença do $V$. harveyi.

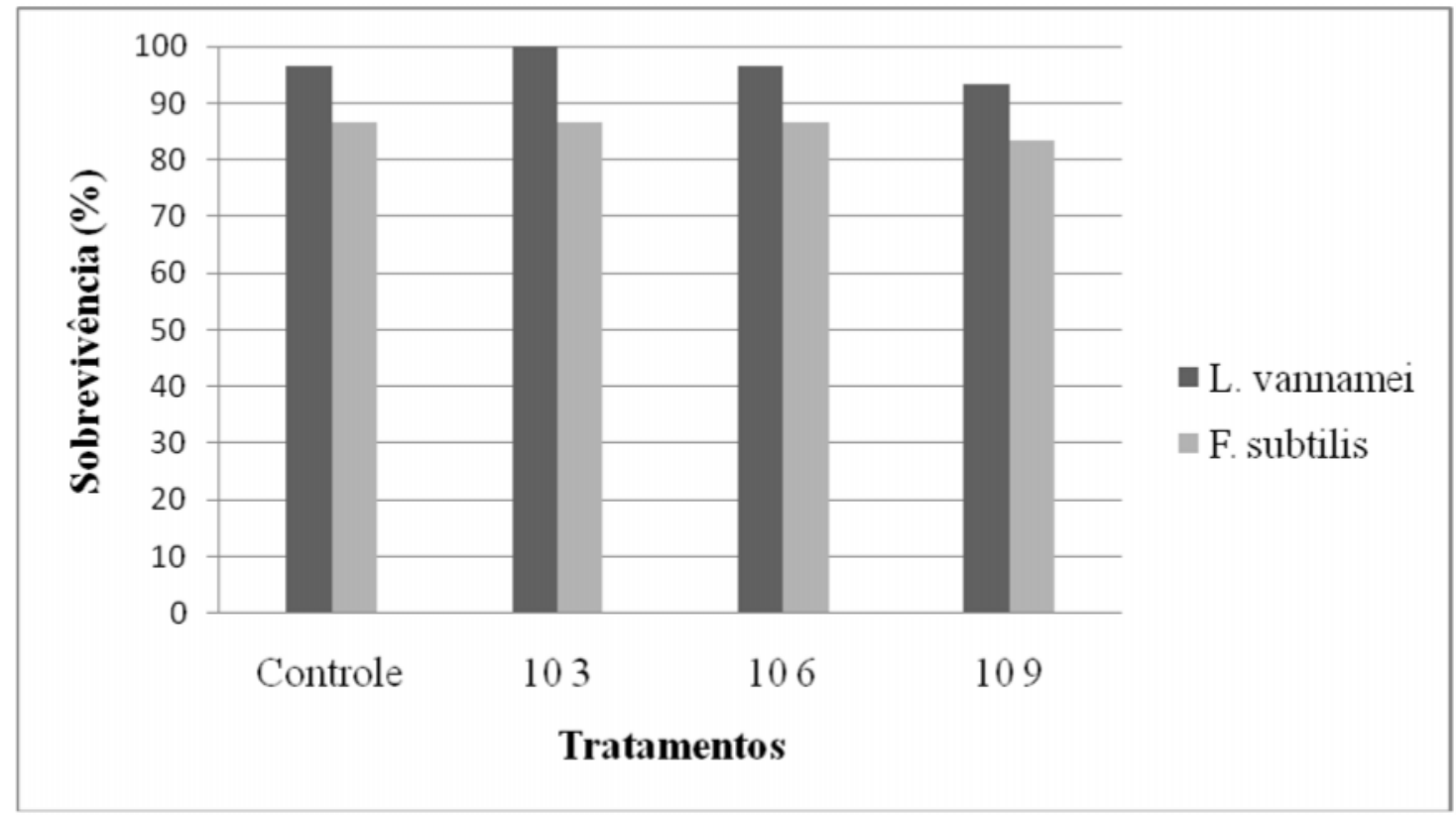

FIGURA 1 - Sobrevivência final do camarão L. vannamei e F. subtilis após infecção experimental por $V$. harveyi $\left(10^{3}, 10^{6}\right.$ e $10^{9}$ UFC $\left.\mathrm{mL}^{-1}\right)$ durante 96 horas.

A concentração inicial de Vibrio spp. nos juvenis de $L$. vannamei e $F$. subtilis foi de $0,83 \times 10^{6}$ UFC $g^{-1}$ e $2,60 \times 10^{6}$ UFC $g^{-1}$, respectivamente. Observou-se uma tendência de aumento na concentração de Vibrio spp. nos camarões infectados com as concentrações mais elevadas de $V$. harveyi $\left(10^{6}\right.$ e $\left.10^{9} \mathrm{UFC} \mathrm{mL}^{-1}\right)$, em relação aos valores iniciais. Os juvenis mantidos no tratamento com $10^{9} \mathrm{UFC} \mathrm{\textrm {mL } ^ { - 1 }}$ de $V$. harveyi, apresentaram concentração final de Vibrio spp. significativamente superior aos demais tratamentos (Tabela 1).

TABELA 1 - Média final ( \pm DP) de Vibrio spp. nos juvenis de L. vannamei e $F$. subtilis expostos à infecção experimental por $V$. harveyi após 96 horas.

\begin{tabular}{lcc}
\hline \multicolumn{1}{c}{ Tratamento } & $\begin{array}{c}\text { L. vannamei } \\
\left(10^{6} \mathrm{UFC} \mathrm{g}^{-1}\right)\end{array}$ & $\begin{array}{c}\text { F. subtilis } \\
\left(10^{6} \mathrm{UFC} \mathrm{g}^{-1}\right)\end{array}$ \\
\hline Controle & $3,00 \pm 0,85^{\mathrm{a}}$ & $1,10 \pm 1,72^{\mathrm{a}}$ \\
$10^{3} \mathrm{UFC} \mathrm{mL}{ }^{-1}$ & $2,72 \pm 1,03^{\mathrm{a}}$ & $2,84 \pm 0,82^{\mathrm{a}}$ \\
$10^{6} \mathrm{UFC} \mathrm{m} \mathrm{^{-1 }}$ & $5,36 \pm 1,79^{\mathrm{a}}$ & $4,48 \pm 1,39^{\mathrm{a}}$ \\
$10^{9} \mathrm{UFC} \mathrm{mL}{ }^{-1}$ & $1.800 \pm 600^{\mathrm{b}}$ & $3.400 \pm 860^{\mathrm{b}}$ \\
\hline Letras diferentes entre tratamentos apresentam diferenças significativas $(\mathrm{p} \geq 0,05)$.
\end{tabular}




\section{DISCUSSÃO}

No presente estudo, a exposição dos animais a diferentes concentrações de $V$. harveyi não causou diferenças na sobrevivência do $L$. vannamei e $F$. subtilis quando comparado aos camarões não expostos. De acordo com Muroga et al. (1994) e Karunasagar et al. (1994), a sobrevivência dos camarões depende do estágio de vida dos indivíduos, além da espécie, das concentrações e linhagem de Vibrio utilizadas. Estudos avaliando infecções de larvas de camarões peneídeos por diferentes linhagens de $V$. harveyi têm apontado resultados conflitantes (SotoRodríguez et al. 2006). Concentrações inferiores a $10^{2}$ UFC $\mathrm{mL}^{-1}$ podem causar mortalidade de mais de $50 \%$ em larvas de $L$. vannamei, enquanto outras linhagens não causam mortalidades em concentrações superiores a $10^{6}$ UFC $\mathrm{mL}^{-1}$ (Prayitno \& Latchford, 1995; Abraham et al., 1997). Aguirre-Guzmán et al. (2001) estudaram o efeito de diferentes espécies de Vibrio sobre a sobrevivência larval de $L$. vannamei e observaram que todos os estágios larvais infectados com V. alginolyticus $\left(10^{5}\right.$ a $\left.10^{7} \mathrm{UFC} \mathrm{mL}^{-1}\right)$ tiveram uma sobrevivência significativamente maior que seus homólogos infectados por $V$. parahaemolyticus, $V$. harveyi e $V$. penaecida. Nesse sentido, nossos resultados indicam que a linhagem utilizada neste experimento não influenciou na sobrevivência dos camarões infectados, durante esta fase do ciclo de vida e período avaliado.

Nossos resultados demonstraram que os juvenis de $L$. vannamei submetidos ao tratamento $10^{3}$ UFC $\mathrm{mL}^{-1}$ apresentaram uma sobrevivência superior do que aqueles mantidos sem a presença do $V$. harveyi. Resultados semelhantes foram encontrados por Aguirre-Guzmán et al. (2002) quando os camarões $L$. vannamei nos estágios de Misis II-III e pós-larva (PL 1) expostos à concentração de $10^{5}$ UFC $\mathrm{mL}^{-1}$ de $V$. alginolyticus apresentaram melhor sobrevivência em relação ao grupo controle.

As bactérias do gênero Vibrio são patógenos oportunistas, sendo consideradas em muitos casos como agentes secundários de infecção. Fatores estressantes tais como falta de alimento, choques de salinidade, exposição a concentrações de amônia, ferimentos ou danos físicos podem funcionar como gatilhos para 0 desenvolvimento de doenças causadas por Vibrio (Phuoc 2008). No presente estudo, a manutenção dos camarões em condições físicas e ambientais adequadas pode ter influenciado positivamente na sobrevivência dos mesmos frente às infecções testadas.

Observou-se uma tendência de aumento na concentração total de Vibrio dos camarões submetidos às maiores concentrações de $V$. harveyi inoculados na água. Por outro lado, Soto-Rodrigues et al (2006) não encontraram nenhuma relação entre a concentração de bactéria inoculada na água e a quantidade de Vibrio encontrada nas larvas de $L$. vannamei durante $48 \mathrm{~h}$ de infecção. Esses mesmos autores sugerem que quando o período de infecção experimental é mais extenso, as larvas são continuamente expostas às bactérias, possibilitando a colonização dos animais. Nossos resultados sugerem que a exposição contínua dos camarões às concentrações pré-determinadas de $V$. harveyi durante o período experimental (96 horas), contribuiu com o aumento da concentração total de Vibrio nos animais, sobretudo naqueles submetidos ao tratamento $10^{9}$ UFC $\mathrm{mL}^{-1}$.

\section{CONCLUSÃO}

Os resultados indicam que as concentrações de $V$. harveyi (linhagem testada) não afetaram a sobrevivência dos camarões $L$. vannamei e $F$. subtilis durante o estágio de vida e período de exposição avaliado. Entretanto, considerando a inexistência de estudos neste tema com o camarão $F$. subtilis, recomenda-se futuras pesquisas enfocando as fases iniciais do ciclo de vida e larvicultura desta espécie.

\section{AGRADECIMENTOS}

Os autores agradecem ao Dr. José Luiz Pedreira Mourino do Laboratório de Camarões Marinhos pertencente à Universidade Federal de Santa Catarina pela doação da linhagem da bactéria Vibrio harveyi utilizada neste estudo.

\section{REFERÊNCIAS}

AGUIRRE-GUZMÁN, G, R VÁZQUEZ-JUÁREZ, F ASCENCIO. 2002. Differences in the susceptibility of American white shrimp larval substages (Litopenaeus vannamel) to four Vibrio species. Journal of Invertebrate Pathology, 78: 215-219.

BATICADOS, MCL, CR LAVILLA-PITOGO, ER CRUZ-LACIERDA, 
LD DE LA PENA, NA SUNAZ. 1990. Studies on the chemical control of luminous bacteria Vibrio harveyi and $V$. splendidus isolated from diseased Penaeus monodon larvae and rearing water. Dis Aquat Org, 9: 133-139.

BOYD, CE, L MASSAAUT. 1999. Risks associated with the use of chemicals in pond aquaculture. Aquaculture Eng. 20: 113-132.

GÓMEZ-GIL, B, L TRON-MAYÉN, A ROQUE, JF TURNBULL, V INGLIS, AL GUERRA-FLORES. 1998. Species of Vibrio isolated from hepatopancreas, haemolymph and digestive tract of apopulation of healthy juvenile Penaeus vannamei. Aquaculture.163: 1-9.

GÓMEZ-GIL B, A ROQUE, JF TURNBULL. 2000. The use and selection of probiotic bacteria for use in the culture of larval aquatic organisms. Aquaculture, 191: 259-270.

KARUNASAGAR, I, R PAI, GR MALATHI, I KARUNASAGAR. 1994. Mass mortality of Penaeus monodon larvae due to antibiotic-resistant Vibrio harveyi infection. Aquaculture, 128: 203-209.

LAVILLA-PITOGO, CRM, CL BATICADOS, ER CRUZ LACIERDA, LD DE LA PEÑA. 1990. Occurrence of luminous bacterial disease of Penaeus monodon larvae in the Philippines. Aquaculture, 91: 1-13.
LAVILLA-PITOGO, CR, EM LEAÑO, MG PANER. 1998. Mortalities of pond-cultured juvenile shrimp, Penaeus monodon, associated with dominance of luminescent vibrios in the rearing environment. Aquaculture, 164: 337-349.

MORIARTY, DJW. 1998. Control of luminous Vibrio species in penaeid aquaculture ponds. Aquaculture, 164: 351-358.

MUROGA, K, K SUZUKI, K ISHIMARU, K NOGAMI. 1994. Vibriosis of swimming crab Portunus trituberculatus in larviculture. J. World Aquacult. Soc., 25: 50-53.

PHUOC, LH. Single and dual experimental infection of specific pathogen-free Litopenaeus vannamei shrimp with White Spot Syndrome Virus and Vibrio species. 2008. PhD thesis, Ghent University.

ROQUE, A, JF TURNBULL, G ESCALANTE. 1998. Development of a bath challenge for the marine shrimp Penaeus vannamei Boone, 1931. Aquaculture, 169: 283-290.

SAULNIER, D, P HAFFTER, C GOARANT, P LEVY, D ANSQUER. 2000. Experimental infection models for shrimp vibriosis studies: a review. Aquaculture, 191: 133-144.

SOTO-RODRíGUEZ, SA, N SIMÕES, A ROQUE, B GÓMEZ-GIL. 2006. Pathogenicity and colonization of Litopenaeus vannamei larvae by luminescent vibrios. Aquaculture, 258: 109-115.

Submetido: $17 / 08 / 2011$

Aceito - 15/02/2012 
